\title{
NOTAS ACERCA DEL DESEQUILIBRIO ESPACIAL DE LAS DISPONIBILIDADES HÍDRICAS EN LA COMUNIDAD VALENCIANA
}

\author{
Concepción Bru Ronda
}

\section{RESUMEN}

Los desequilibrios hídricos en la Comunidad Valenciana y la presencia de déficits en algunas de sus comarcas es un hecho percibido desde antaño. Sin embargo, los desfases entre recursos y demandas provocados por el notable incremento de estas últimas en la segunda mitad de siglo y para todo el ámbito valenciano, han agudizado estos desequilibrios. Diversas iniciativas han tendido desde épocas históricas a paliar estos desajustes si bien en la actualidad los cambios socioeconómicos y tecnológicos requieren una renovación en los sistemas de economía del agua, que deben estar basados, en síntesis, en una gestión integral, racional y comunitaria de los mismos.

\begin{abstract}
Water problems in the Comunity of Valencia with the existence of shortages in some areas is a fact that has been detected since long ago, this matter is marked before hand by the climatological conditions. The outstanding increase of water demand during the second half of the Century has intensified the unbalance between resources and demands. Throughout history several initiatives have tried to reduce these problems. At present the socioeconomic and technological changes call for a reorganization of the systems of water economy which should be based, in synthesis in a wholesome effort, national, integral and communitary.
\end{abstract}


La carencia de recursos hídricos en la Comunidad Valenciana se localiza, mayormente, en algunas comarcas, y viene definida a priori por las condiciones climatológicas (1) imperantes en este ámbito, y que se traducen, en esencia, en un desequilibrio espacial de las precipitaciones, que, a mayor abundancia, presentan fuertes irregularidades estacionales e interanuales.

Aleatoriedad y restringida presencia del agua útil, en ciertos espacios, ha determinado la aparición de desequilibrios hídricos, y, es más aún, de déficits en el territorio valenciano. Este hecho, percibido ya en tiempos históricos, propició el desarrollo de toda suerte de iniciativas y técnicas hidráulicas tendentes a la regulación y aprovechamiento de las aguas, cuyos antecedentes más remotos se refieren a época romana y árabe. Vestigios arqueológicos de esta naturaleza y raigambre abundan por doquier y son prueba de un problema consustancial a la fachada levantina. Cavanilles en el siglo XVIII plasma con meridiana claridad dicha realidad hídrica en varios de los capítulos de su libro Observaciones sobre la Historia Natural, Geografía, Agricultura, Población y Frutos del Reino de Valencia (2). Su lectura minuciosa aporta sugestivos ejemplos de las dicotomías existentes en materia de recursos de agua, agudizadas, ele otra parte, por la interacción de varios condicionantes: físicos, humanos, culturales y económicos.

La indigencia hídrica es por lo tanto un hecho manifiesto en varios enclaves del espacio regional valenciano, que vienen reclamando tradicionalmente mayores dotaciones; si bien desde mediados de siglo dichas peticiones van a intensificarse y a generalizarse para otros espacios que antaño no sufrían déficits. Así pues surgen mayores demandas en relación con el incremento de las necesidades, pero también con la creación de nuevos usos del agua que compiten con los existentes. Frente al mayor consumidor de agua, que venía siendo el regadío, hoy se sitúan los abastecimientos a ciudades, núcleos turísticos e instalaciones industriales.

En el momento actual, el desfase entre recursos y demandas es una realidad preocupante, ya que sin haberse producido apenas incrementos en los recursos disponibles, las demandas han crecido hasta duplicar y casi triplicar las existentes a principio de siglo, sobre todo en las tierras más meridionales.

Para entender la problemática que se nos avecina es necesario realizar un análisis de disponibilidades hídricas, seguido de un examen de los diferentes usos del agua, para concluir con unas reflexiones sobre cómo se solucionaron las carencias en el pasado y cómo se pueden afrontar de cara al presente. 


\section{Disponibilidades hídricas}

Por lo que se refiere a los recursos totales de los ríos valencianos, suman algo más de $3.000 \mathrm{Hm}^{3}$ anuales, según se observa en el cuadro I (aunque los recursos globales superficiales ascienden a casi el doble). De su examen se desprende que en la distribución tipológica y espacial se detectan los mayores colectores, o por lo menos los de los caudales más voluminosos, hacia la mitad centro del país, hecho que aporta un dato más hacia la comprensión de los desequilibrios hídricos.

\section{CUADRO 1}

Recursos totales en $\mathrm{Hm}^{3}$ /año de los ríos valencianos

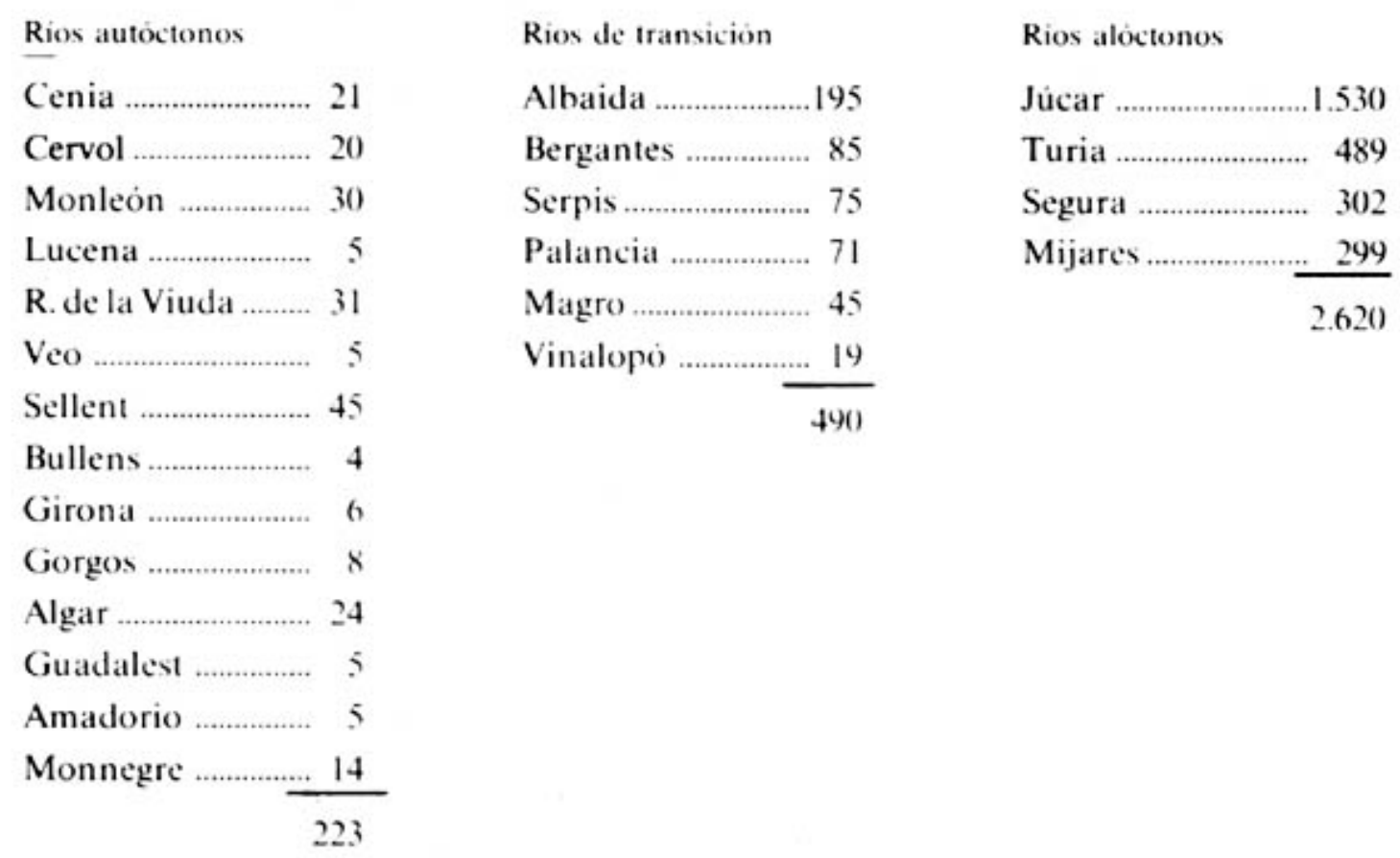

Globalmente se puede decir que los ríos valencianos tienen unos recursos superficiales escasos, exceptuando los alóctonos, pero que son intensamente aprovechados mediante obras de acopio y regulación, capaces de proporcionar la continuidad en el abastecimiento y la disposición de los caudales necesarios. A la escasez citada hay que contraponer un hecho que constituye una muestra más de la disparidad hídrica y de su temporalidad, y que origina el fenómeno de las crecidas, aspecto consustancial a la vertiente mediterránea y que en la Comunidad Valenciana se manifiesta con gran asiduidad.

Sería desconocer la realidad del problema el ignorar la íntima relación que guarda la escorrentía subterránea con la anterior. Hasta tal punto ésta es estrecha 
que los caudales superficiales en la mayoría de las cuencas fluviales dependen de las resurgencias kársticas que les proporcionan débitos constantes y naturalmente regulados.

Los acuíferos que encontramos en la Comunidad Valenciana se desglosan en: unidades calizo dolomíticas del Mesozoíco y Terciario (3), de grandes y medianas dimensiones, y que dan lugar a sistemas acuíferos de cierta capacidad; unidades hidrogeológicas de menor potencial las constituyen algunas planicies de rellenos detríticos, de Edad Neógena; y, por último, acuíferos interesantes con los depósitos cuaternarios detríticos, producto de aportes fluviales, que forman rellenos en los sectores costeros principalmente.

En total, proporcionan unos recursos próximos a los $1.500 \mathrm{Hm}^{3}$ anuales, situándose los mayores complejos acuíferos en el sector Norte de la Comunidad Valenciana, los cuales albergan el $90 \%$ de los recursos subterráneos totales. Hay que matizar, no obstante, que la existencia de acuíferos profundos no es sinónimo de equilibrio hídrico, ya que en algunos casos, como en la Plana de Castellón y Vinaroz, sectores de la Marina Baja o Vega del Segura, problemas concretos de salinización (por intrusión marina o por contaminación química), no regulación o sobreexplotación, dan lugar a déficits importantes, presentes o futuros.

\section{Usos del agua}

Hasta ahora se ha hablado de recursos hídricos y de su distribución espacial en base a hechos físicos. Esto, a priori, señala un desigual reparto, pero los desequilibrios nacen no sólo de la existencia o carencia de volúmenes de aguas disponibles, sino que intervienen en ellos factores humanos y, por ende, económicos que mediatizan las demandas de agua en base a unos usos creados, entre los que cabe distinguir sintéticamente: el urbano, el agrario y el industrial.

Por lo que respecta al primero, el uso urbano, viene definido por la población existente y su reparto. En los momentos actuales, la Comunidad Valenciana cuenta con más de 3.700.000 habitantes, pero distribuidos con extraordinaria desigualdad dentro del mismo territorio. Los valores mínimos de la densidad de población se dan en las comarcas de Els Ports y del Rincón de Ademuz, con $8 \mathrm{Hab} / \mathrm{Km}^{2}$ y el máximo en la comarca de L'Horta, con $2.046 \mathrm{Hab} / \mathrm{Km}^{2}$. Si bien los índices de densidades por provincias son más indicativos, ya que éstos son: en la de Castellón, $65 \mathrm{Hab} / \mathrm{Km}^{2}$; en la de Valencia, 191; y en la de Alicante, 208, siendo esta última la más uniformemente poblada y la de mayor tasa de crecimiento. Si se analizan los consumos referentes a este uso en el que se incluye el industrial y el turístico, la distribución por provincias es la siguiente: Castellón consume 75,39 $\mathrm{Hm}^{3}$ /año, Valencia 261,51, y Alicante, 129,17, que comportan el 16\% del total de los volúmenes de agua demandada, de los cuales el $60 \%$ son de origen subterráneo y el resto de aguas superficiales. 


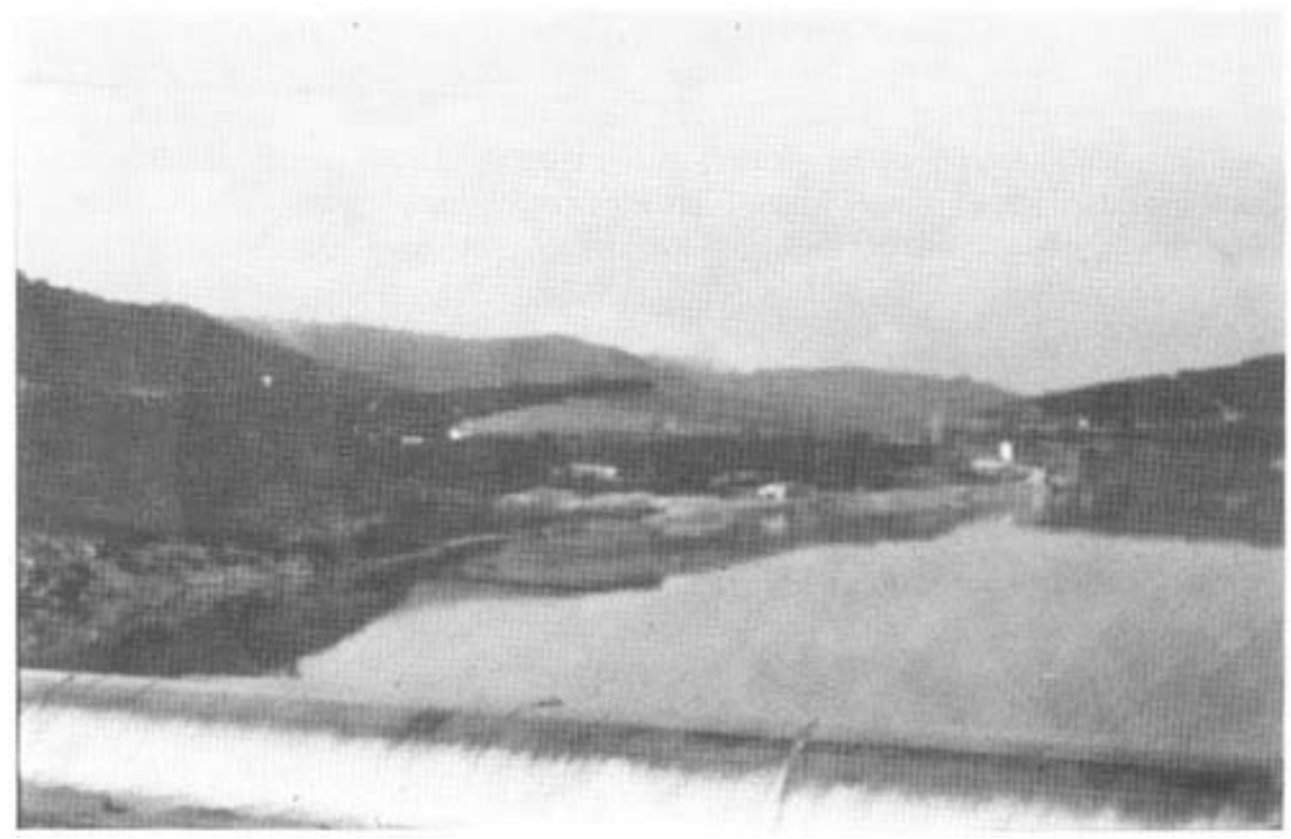

Azud en la cuenca del río Júcar, aguas abajo de Tous.

Apréciese la abundancia de aguas.

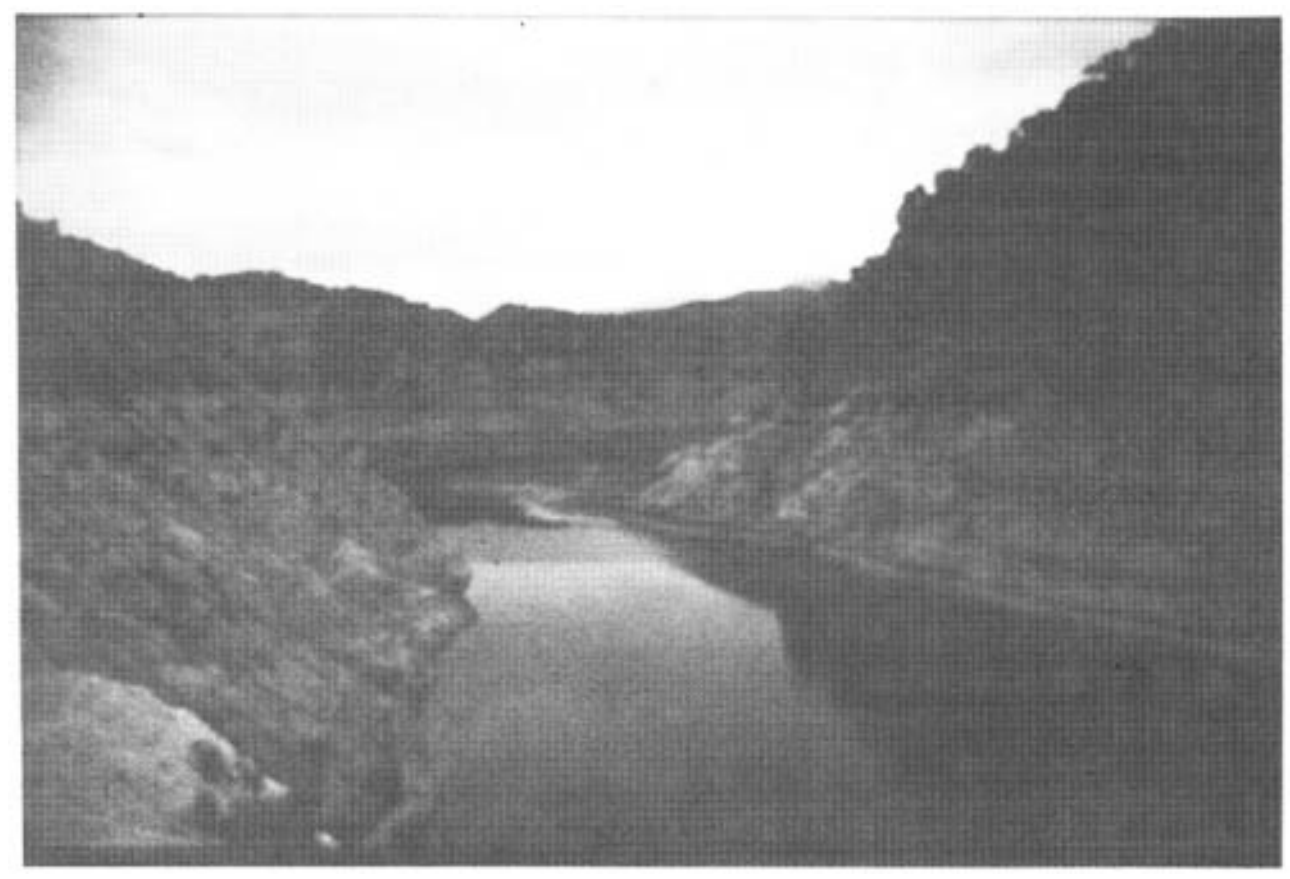

Situación de aguas bajas que presenta comúnmente el embalse de Tibi, cabecera de uno de los sistemas de riego más tradicionales de la provincia alicantina. 
Como se ha señalado anteriormente, el uso más importante la constituye el regadío, ya que acapara el mayor volumen de recursos utilizados $\left(2.434 \mathrm{Hm}^{3} / \mathrm{año}\right)$. Actualmente existen unas $323.800 \mathrm{Ha}$., aproximadamente, con una dotación media de $7.600 \mathrm{~m}^{3} /$ año, pero su distribución espacial, así como las dotaciones correspondientes, son muy irregulares en cantidad y en origen. Del total de la superficie regada, $181.200 \mathrm{Ha}$. lo son con recursos superficiales (56\%), y 126.200 con aguas subterráneas (39\%) y las 16.000 restantes son regadíos mixtos (4,9 por ciento).

En el cuadro II se resumen los regadíos por provincias, según la procedencia del agua y su demanda en $\mathrm{Hm}^{3}$. Cabe destacar que Valencia acapara el 49,9\% de la superficie regada y utiliza el 53,9\% de los recursos; Alicante tiene el 38,4\% de los regadíos y consume el $26,2 \%$ de recursos; y por último, Castellón, con el 21,4\% del regadío, y un consumo del 19,8\% del agua. Son cifras éstas que muestran las disparidades existentes entre las tres provincias en relación a los sectores regados y las respectivas demandas, hecho que queda vinculado a las disponibilidades existentes en cada uno de los espacios provinciales.

\section{CUADRO 2}

Superficies de regadío en Ha. y demandas en $\mathrm{Hm}^{3}$ /año por provincias.

El examen de las dotaciones medias para los regadíos en las diferentes cuencas muestra,

\begin{tabular}{|c|c|c|c|c|c|c|c|c|}
\hline Provincias & Regadio & ag. Superf. & Regadi & s ag. Subt. & Regadi & os mixtos & & TAL \\
\hline & Superf. & Demanda & Superf. & Demanda & Superf. & Demanda & Superf. & Demanda \\
\hline Castellón & 20.800 & 174 & 34.800 & 211 & 13.800 & 99 & 69.400 & 483 \\
\hline Valencia & 88.500 & 1.032 & 69.300 & 262 & 2.200 & 18 & 160.000 & 1.312 \\
\hline Alicante & 72.300 & 430 & 52.100 & 209 & - & - & 124.400 & 639 \\
\hline OTAL & & & & & & & 323.800 & 2.434 \\
\hline
\end{tabular}

asimismo, la gran heterogeneidad vigente. A modo de ejemplo basta comparar los elevados gastos de agua de los cultivos de huerta de los ríos Júcar y Turia, donde la abundancia de aguas hace que se riegue en exceso, con dotaciones del orden de $\operatorname{los} 14.500 \mathrm{~m}^{3} / \mathrm{Ha} /$ año y los de los ríos Algar, Guadalest, Vinalopó o Monnegre, donde las dotaciones son bajas, del orden de los 4.000 y $3.000 \mathrm{~m}^{3} / \mathrm{Ha} /$ año. En este último caso la escasez del agua implica mejores aprovechamientos y consumos notablemente restringidos. 


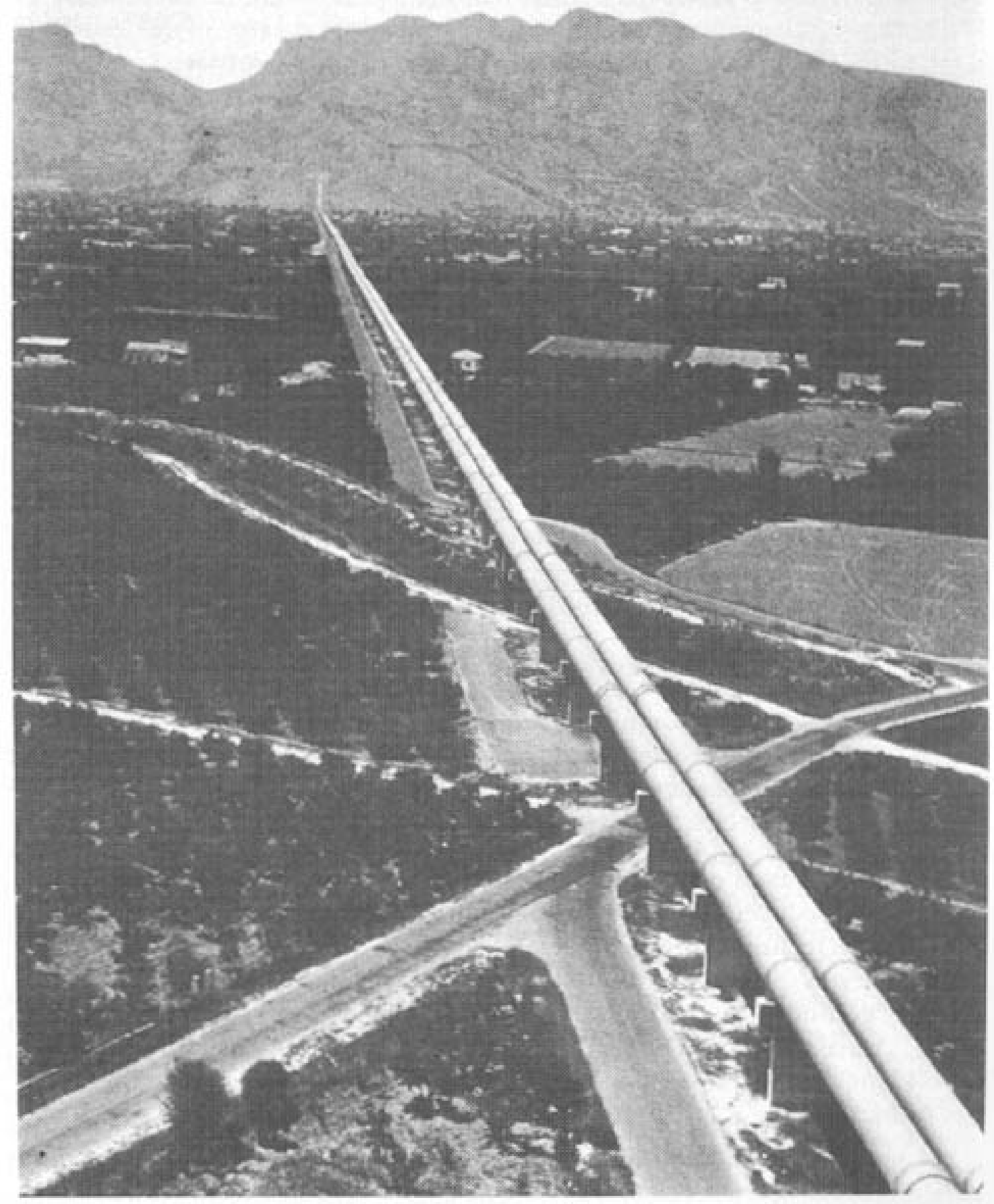

Infraestructura del trasvase Tajo-Segura a su paso por Orihuela. Este constituye uno de los proyectos más ambiciosos para solucionar el desequilibrio hidrográfico de las cuencas surestinas. 


\section{CUADRO 3}

Balances hídricos por unidades de gestión en la Comunidad Valenciana

\begin{tabular}{|c|c|c|c|c|c|c|c|c|c|c|}
\hline \multirow{3}{*}{ INIDADIS } & \multicolumn{3}{|c|}{ INTK NDAS $\mathrm{Hm}^{*}$} & \multicolumn{5}{|c|}{ SALIDAS $\mathrm{Hm}^{2}$} & \multirow[b]{2}{*}{ TOTAL } & \multirow[b]{2}{*}{$\begin{array}{c}\text { DEFlu } 1^{\circ} \\
\mathrm{Hm}^{\prime}\end{array}$} \\
\hline & $\begin{array}{l}\text { Rusm- } \\
\text { sapat }\end{array}$ & $\begin{array}{l}\text { cantrows } \\
\text { whtert. }\end{array}$ & $\begin{array}{l}\text { Intratas } \\
\text { otro lish }\end{array}$ & Torial & $\begin{array}{l}\text { Kemand } \\
\text { urtbaita }\end{array}$ & $\begin{array}{l}\text { Deinand } \\
\text { astricola }\end{array}$ & $\begin{array}{l}\text { Salidas n } \\
\text { reguladat }\end{array}$ & & & \\
\hline & & & & & & & otar & At mat & & \\
\hline Hs Ports & 86 & - & - & 86 & & 1 & 85 & - & 86 & - \\
\hline Planas de Vinaroz-Torrbla. & $4 i$ & 20 & 244 & 305 & 6 & 85 & 24 & 219 & 336 & 31 \\
\hline Rambla de La Vinda............ & 30 & 257 & - & 293 & & 6 & 287 & - & 293 & - \\
\hline 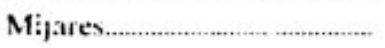 & 119 & - & 180 & 299 & & 19 & 280 & - & 299 & - \\
\hline 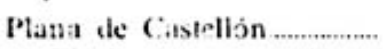 & 316 & 76 & 12 & 404 & 37 & 281 & - & 89 & 407 & 3 \\
\hline Palancia & x! & 55 & - & 136 & 2:3 & 93 & 35 & 2 & 150 & $1 \cdot 1$ \\
\hline Turid Mctio...... . & 509 & 125 & - & 634 & 15 & 146 & 413 & - & 574 & -6 \\
\hline 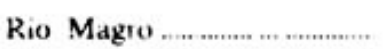 & +5 & - & - & 45 & si & 6 & - & - & 61 & -1, \\
\hline 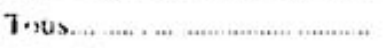 & $1.531)$ & 125 & - & 1.655 & 21 & 32 & 1.602 & - & 1.655 & - \\
\hline 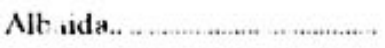 & 267 & - & - & 267 & 17 & $\$ 7$ & 193 & - & 267 & - \\
\hline Plana de Vatenci. & $20 \leq 1$ & 565 & $: 30$ & 2.746 & 175 & 1.141 & 953 & 796 & 2.965 & $2 ! 9$ \\
\hline Serpis - Pi. de Gandta & 75 & 61 & - & 136 & 20 & 70 & 25 & 21 & 136 & - \\
\hline Marina Altu & 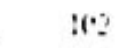 & 68 & . & $i 70$ & 13 & 75 & - & 87 & 175 & ; \\
\hline Mrrina taja......... & 33 & s & - & 41 & 22 & 31 & 4 & - & 57 & 16 \\
\hline I: Viacani & $1:$ & 2 & i1. 40 & 56 & 37 & 30 & (2) - & - & 67 & $::$ \\
\hline 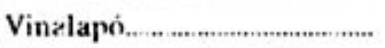 & 19 & 53 & - & 72 & 1: & 122 & 14 & - & 153 & r. \\
\hline Baju Seguria - liajo Vin........ & $30^{\circ}$ & - & 360 & $+6,2$ & 30 & 480 & - & (6) & 570 & .80 \\
\hline
\end{tabular}

Fuente: Libro Blanco del Agua en la Comunidad Valenciana. Consellería de Obras Públicas y Urbanismo. 1985.

(1) Importación.

(2) Exportación.

De los dos usos consuntivos que se acaban de analizar (abastecimiento y regadío), se deducen unas demandas totales próximas a los $3.000 \mathrm{Hm}^{3} / \mathrm{año}$, y existen unos recursos aprovechables del orden de $7.800 \mathrm{Hm}^{3}$ /año, a pesar de los cuales, y según se desprende del análisis del balance hídrico de las distintas unidades de gestión hidrológica, establecidas en el Plan Hidrológico Nacional (cuadro III), no se sufragan las necesidades a nivel comunitario, existiendo un déficit de $444 \mathrm{Hm}^{3}$, hecho que denuncia el desequilibrio espacial de las disponibilidades hídricas frente a las demandas establecidas.

Un análisis rápido por provincias establece que Castellón cuenta con un déficit mínimo teórico, por lo que cabría suponer que se trata de una zona sin problemas de recursos, ya que de otro lado presenta unas salidas al mar $y$ a otras unidades importantes, que superan los $700 \mathrm{Hm}^{3}$. Sin embargo la situación de esta provincia es delicada, ya que existen recursos sin regulación en el Río Palancia, 
principalmente, y presenta, además, en la franja litoral, más humanizada, serios problemas de sobreexplotación de acuíferos y fenómenos graves de intrusión marina.

En la provincia de Valencia los déficits teóricos superan los $200 \mathrm{Hm}^{3}$, pero de otro lado, más de $1.500 \mathrm{Hm}^{3}$ se pierden a través de salidas al mar o hacia otras unidades. Además de los problemas de escasez de recursos son muy puntuales y obedecen casi siempre a una falta de regulación de las cuencas y de control de la extracción de aguas profundas.

Por lo que concierne a la provincia de Alicante, la situación es realmente crítica, ya que los recursos propios útiles no son suficientes para satisfacer las demandas en general, incluso previendo una total regulación de las cuencas. Las unidades hidrogeológicas, salvo alguna zona de la Marina Alta, en la que se producen salidas al mar, o de la Montaña, que se encuentra en equilibrio, son fuertemente deficitarias y además de sobreexplotar los acuíferos subterráneos y reutilizar aguas depuradas, requieren la importación de recursos externos.

\section{Desequilibrios hídricos: soluciones del pasado y alternativas de futuro}

La inestabilidad y precariedad hídrica del conjunto de sistemas hidráulicos de la Comunidad Valenciana es un hecho que queda evidenciado en las diversas actitudes que el hombre de estas tierras ha venido tomando desde tiempos históricos. Si bien los desequilibrios presentan una doble faceta que se manifiesta de Norte a Sur, mostrando aspectos muy diferentes del problema, que han requerido por ello soluciones igualmente bien distintas.

En una gradación desde el Norte del país hacia el extremo meridional, las condiciones climáticas, y en general geográficas, deciden que en la zona septentrional las actuaciones antrópicas se hayan encaminado preferentemente en un pasado a perfeccionar los sistemas hídricos de regulación, distribución y saneamiento. En la zona Sur a todas esta vertientes de los aprovechamientos hídricos se les añade un complejo y desarrollado sistema de derivación y acopio, encaminado a aprovechar y retener caudales exiguos y adventicios.

Con el avance de los siglos los incrementos demográficos y los cambios geoeconómicos han venido introduciendo nuevas y crecientes demandas, y en cierto modo han extremado el problema de los desequilibrios hídricos, al tiempo que han extendido el concepto de déficit hacia otros espacios antes ajenos a él. Con ello se ha conseguido unificar la crisis de la situación hidráulica para toda la Comunidad Valenciana, aunque dentro de ella, y aunque sea por cuestiones estrictamente climáticas, los desfases entre recursos y demandas siguen siendo mayores en su extremo meridional. Ante esta situación, toda suerte de iniciativas históricas, las cuales serio prolijo enumerar, encaminadas a satisfacer las demandas y que han venido siendo aplicadas en un espacio con sobrado renombre en cuestiones hídricas, han quedado menguadas en su eficacia, demostrando con ello la necesidad de incorporar nuevas medidas y actuaciones más acordes con los actuales sistemas de producción. 
La fragilidad del elemento agua en la naturaleza ha venido a demostrar que su uso y consumo debe realizarse dentro de un contexto de racionalización y gestión integral, conceptos ambos que tienen su primer fundamento en el conocimiento profundo de las condiciones del medio físico (y en concreto del marco hidrogeológico) y de las modificaciones que el hombre pueda introducir sobre él, tanto en el presente como en el futuro. Estos aspectos de ordinario han sido abordados con poca profundidad y escasa perspectiva, lo que ha determinado serias afecciones y situaciones deficitarias no del todo naturales desde el punto de vista estrictamente medioambiental.

Partiendo de esa base, en segundo término se hace imprescindible la adaptación cultural-técnica y psicológica a la nueva situación social-hídrica, y arbitrar de acuerdo a ella los comportamientos necesarios. Estos prolegómenos son inherentes a cualquier tipo de política y gestión hidráulica coherente, y se yuxtaponen y complementan en todo momento a cualquier tipo de actuación.

Dentro de las medidas que podríamos llamar directas, por su incidencia en el medio y en la economía, se sitúan aquellas relativas al ahorro hidráulico (concepto no difundido muy ampliamente). Es decir, aquellas que conducen al uso racional del recurso, y que comienzan tanto por la mejora en la gestión, en la infraestructura y en los sistemas de distribución y técnicas del regadío, como en la adecuación de las redes de suministro urbano, y la posible reutilización de las aguas residuales una vez depuradas. Este tipo de actuaciones significarían rescatar un porcentaje muy importante de los recursos que hoy se pierden, y cuyo integral aprovechamiento marca la línea de una nueva economía del agua.

Otra línea de trabajo dentro de las soluciones presentes y futuras, pero no por ello nada nuevas, la constituye el incremento de las obras de regulación y aprovechamiento en las cuencas que adolecen de ellas. En este sentido cabe precisar que los obstáculos a veces son insalvables, sin embargo resulta tan decisivo implantar nuevas infraestructuras, como recuperar, reincorporar y adaptar las ya existentes a las recientes y vanguardistas alternativas de ahorro de agua y consumo.

Solución que viene siendo efectiva desde inmemorial tiempo para las áreas con mayores carencias, es la de los trasvases entre cuencas. Es quizás este método el más arraigado en la opinión pública cuando piensa en la solución de un desequilibrio hídrico. Estas obras de ingeniería hidráulica han sido durante tiempo las más atractivas y socorridas, y en muchas ocasiones también carentes de un planteamiento aséptico, sopesado y racional, como fue el que pudo establecer el Plan de Obras Hidráulicas de 1933. La tentativa de los trasvases constituye de hecho una solución evidente para las áreas en las cuales se vienen produciendo déficits insalvables mediante recursos locales, pero ella sola no debe ser la regeneradora de la economía hídrica del área afectada, sino que deben confluir y actuar todas las otras alternativas ya apuntadas.

Analizando casos concretos, la provincia de Alicante ha sido la más 
beneficiada en este último aspecto de la gestión hidráulica. El trasvase Tajo-Segura se concretó en 1979, cuando comenzaron a llegar las aguas al SE peninsular y en cierto modo ha sido la culminación de una larga historia de proyectos de regulación, viajes de aguas y avatares hídricos (5). Esta colosal inversión no ha sido, sin embargo y con todo, la respuesta única y global a los déficits alicantinos, los cuales han sido causa y estímulo en la última década de un crecimiento en los sistemas de aprovechamiento hídrico. Una fase de sequía (1978-1984) previa a la llegada del trasvase condicionó un desarrollo inusitado de las técnicas de captación, regulación, embalse, distribución, regadío total y reciclaje de aguas residuales. Todo ello ha supuesto la superación de un déficit en una etapa crítica y ha servido para abrir nuevas luces dentro del concepto tradicional de la economía hídrica alicantina (6).

Las otras dos provincias, Castellón y Valencia, menos acuciadas tradicionalmente por los déficits no han estimulado suficientemente la aplicación de estos métodos recientes, los cuales se encuentran en gran medida en período de planificación o proyecto. Otra cosa se puede decir de los trasvases, de los que desde hace tiempo existen ideas prefijadas. Es el caso del Canal del Júcar-Turia para cubrir los déficits de abastecimiento de la ciudad de Valencia y para ayudar a varios regadíos de la comarca de L'Horta, Camp del Turia y cuenca del río Magro; u otro canal, que procedente del Ebro, discurre entre Cherta y Calig, y que es un antiguo proyecto recuperado del Plan Nacional de Obras Hidráulicas de 1933, y hoy en fase de ejecución, mediante el cual se posibilitaría el auxilio necesario a las tierras castellonenses.

Estas trasfusiones suelen ser dramáticas, ya que conllevan por parte de las cuencas cedentes un miedo psicológico en cuanto que supone esa cesión una hipoteca de futuro para ellas. Con todo las necesidades incuestionables de ciertas zonas han obligado a éstas a superponerse y a luchar contra obstáculos, y sobre todo contra ciertos muros de insolaridad, logrando hacer efectivos estos trasvases. Esto ha sido a menudo posible dentro de las mismas provincias, consiguiendo con ello una redistribución interna de los recursos (caso de Alicante), pero los trasvases entre cuencas interprovinciales no han visto todavía la luz. El proyecto Júcar-Vinalopó, sin ir más lejos, con una trayectoria de más de seis siglos, continúa incólume y es de pensar que su proyección futura quede todavía lejana. En ello inciden diversos puntos, entre los que destacan las mayores y crecientes demandas del área metropolitana de Valencia y el proyecto de ampliación del Canal del Júcar y del regadío valenciano (7). Además se cierne sobre esta cuenca el continuo cribado de los acuíferos de La Mancha, donde se sitúa la cabecera del Júcar, que vienen mermando progresivamente caudales a este río.

Concluyendo, puede establecerse que la complejidad de la economía hídrica requiere de un análisis pormenorizado y profundo de todas las facetas que la integran, y que fuera de apasionamiento y egoísmos particulares, obedece su 
éxito a una gestión racional, integral, innovada y comunitaria, en el seno de la cual los desequilibrios hídricos podrán ser planteados con claridad y tal vez solucionados.

\section{BIBLIOGRAFÍA}

1. ClAVERO PARICIO, P. L., Los climas en la región valenciana. Tesis Doctoral. Universidad de Barcelona. 1980.

2. CAVANILLES, A. J., Observaciones sobre la Historia Natural, Geografía, Agricultura, Población y Frutos del Reyno de Valencia. Imprenta Real. Madrid. 1975.

3. RODRÍGUEZ ESTRELLA, T., «Las aguas subterráneas de la Comunidad Valenciana». Revista El Campo. Banco de Bilbao. Madrid. 1987.

4. CONSELLERIA DE OBRAS PÚBLICAS Y URBANISMO, Libro Blanco del Agua en la Comunidad Valenciana. 1985.

5. BRU RONDA. C., «Pasado, presente y futuro de un proyecto polémico: el trasvase Júcar-Vinalopó». En Coloquio sobre Demanda y Economía del Agua en España. Alicante, noviembre de 1986.

6. BRU RONDA, C., «Hacia una nueva economía del agua: la reutilización de aguas depuradas en el espacio alicantino». Revista Idealidad. Caja de Ahorros de Alicante y Murcia. Alicante. Enero-Febrero de 1987.

7. DOMINGO PÉREZ, C., «El trasvase Júcar-Turia». En Coloquio sobre Demanda y Economía del Agua en España. Alicante, noviembre de 1986. 